\title{
Effect of preozonation and prechlorination on total organic carbon removal in surface water treatment in Iran
}

\author{
A. Torabian ${ }^{1}$, A. A. Ghadimkhani ${ }^{1}$, A. Rashidi Mehrabadi ${ }^{2}$, \\ M. Shokouhi ${ }^{1}$ \& R. Heidarzadeh ${ }^{1}$ \\ ${ }^{1}$ University of Tehran, Iran \\ ${ }^{2}$ Power and Water University of Technology, Tehran, Iran
}

\begin{abstract}
In drinking water treatment, prechlorination and preozonation are often applied in order to control micro-organisms and taste and odour causing materials, which may influence organics removal by pre-oxidation and adsorption.

Using commercial and natural water humid substances, the positive effect of prechlorination and preozonation as an aid to coagulation-flocculation of these compounds were confirmed by the removal of total organic carbon (TOC). These experiments were conducted at bench-scale through a series of jar tests using different $\mathrm{pH}$, coagulant dosage and TOC concentration of approx. 4, 8 and $12 \mathrm{mg} / \mathrm{l}$. In addition to TOC removal, the existence of an optimum preozonation dose and an optimum prechlorination dose were also confirmed. Experiments show that prechlorination and preozonation can improve coagulation and flocculation depended on TOC concentration of influent surface raw water. The results demonstrate a differential effect between prechlorination and preozonation on removal of TOC. Preozonation showed a positive effect on a system with low influent TOC and very low molecular weight (noncolloidal) humic substances.
\end{abstract}

Keywords: prechlorination, preozonation, TOC, surface raw water, preoxidation.

\section{Introduction}

In the early 1900s, the United States' drinking water industry drastically reduced the number of fatal waterborne disease outbreaks when it began chlorinating 
drinking water. Some ninety years later, the United States Environmental Protection Agency imposed stringent regulations governing chlorination of drinking water supplies because this same chemical, which had saved so many lives, produced suspected carcinogens in the presence of naturally occurring organic matter (Letterman [11]).

Two groups of these potential carcinogens are trihalomethanes (THMs) and haloacetic acids (HAAs). Both form when chlorine reacts with natural organic matter in raw water. According to the 1995 Community Water Systems Survey conducted by the US Environmental Protection Agency (USEPA), 14.2\% of surface water treatment systems servicing a population of 50,001-100,000 are using $\mathrm{ClO} 2$ as a predisinfectant compared to $47.5 \%$ using chlorine, $15.5 \%$ using chloramines, and 5.4\% using ozone (USEPA [8]).

Although ozone can destroy phenolic compounds structure effectively, it is not economical to reduce the TOC to an acceptable level using single ozonation process due to high ozonation cost [10].

Unfortunately, the anticipated maximum contaminant levels for haloacetic acids (HAAs) and trihalomethanes (THMs) of certain source water may not be using enhanced coagulation (Crozes et al. [5]). Thus, the conventional water treatment process with coagulation/sedimentation and filtration is unable to remove a significant amount of natural organic matter (NOM) [14].

Because of the formation of DBP, more advanced technologies including oxidation, adsorption, and membrane filtration were introduced to remove NOM prior to disinfection process. Ozone has been used as a strong oxidant for years, and several researches (Amy et al. [1], Jacangelo et al. [7]) have shown that ozonation prior to chlorination can lower formation potential of THM and HAA [15].

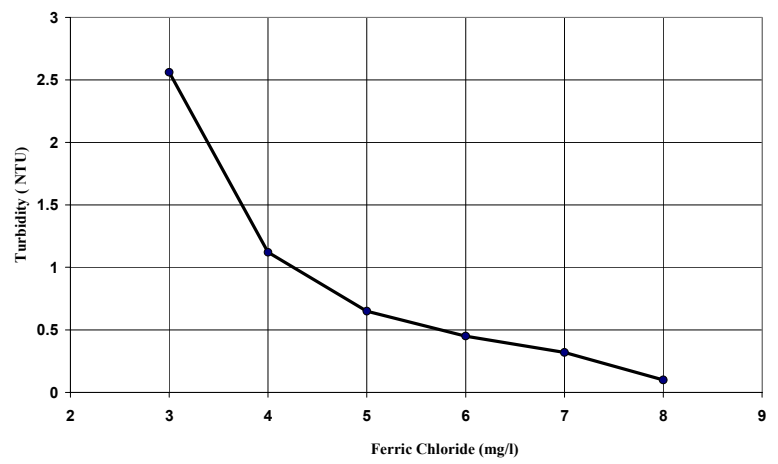

Figure 1: Coagulant only jar test result for turbidity removal of humic acid synthetic water.

It has been reported that ozonation could convert NOM from humic substances to non-humic fractions and from higher- to lower-MW fractions (Amy et al. [1] Owen et al. [13]). In the preozonation process, ozone is added to source water prior to coagulation. The role of ozone acts as an oxidant 
sometimes as a coagulant-aid. The dosage of preozonation to achieve the best coagulation ranges from 0.4 to $0.8 \mathrm{mg} \mathrm{O} 3 / \mathrm{mg}$ carbon [4].

A study by Edwards and Benjamin examined the effect of preozonation on between coagulant and natural organic matter (NOM) and found that increasing the ozone dosage led to increase in metal residuals for both Iron and aluminiumbased coagulants. As the zeta potential increased (became less negative) with increasing coagulant dosage, less metal residual was detected [6].

As the ozonation dosages increased, however, the flocs became more highly charged (more negative), and thus the critical coagulants (CCC) was increased for increasing ozone dosage. TOC removal was sometimes increased and sometimes decreased, depending on ozonation dosage and coagulant dosage. However, the amount of TOC removal by coagulation decreased with increasing ozone dosage because of transformation of NOM into more hydrophilic, less absorbable molecules. Overall TOC removal slightly increased with increasing ozone dosage at very high and low coagulant dosages but decreased at moderate coagulant dosages [6].

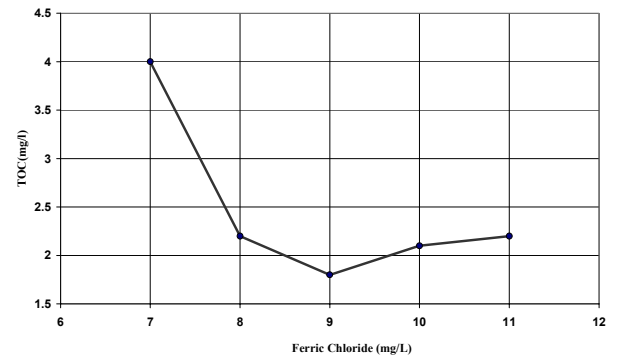

Figure 2: Coagulant only jar test result for TOC removal of humic acid synthetic water.

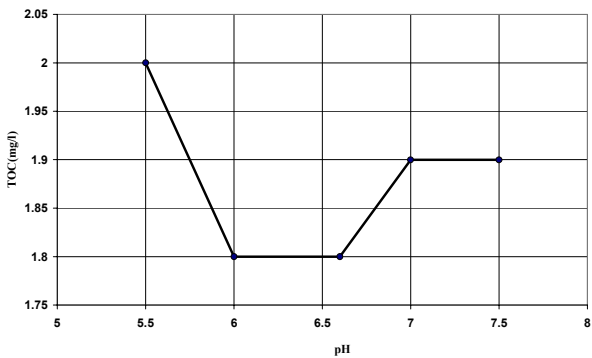

Figure 3: Coagulant only jar test result for turbidity removal of humic acid synthetic water.

Edwards and Benjamin concluded that at constant $\mathrm{pH}$, the dosage of metal salt coagulants required for optimal particulate removal in the presence of NOM increased with increasing ozone dosage. For organic polymer coagulants, however, the opposite proved true [6]. 
Becker found that oxalate (a common ozonation by-product) had an adverse effect on coagulation and filtration of turbidity and TOC when alum was used as the only coagulant [3].

Schneider and Tobiason concluded that when alum is used as a coagulant, preozonation leads to increases in settled water turbidity, TOC removal, and DOC at the conditions tested $(0.5$ to $0.8 \mathrm{mg} / \mathrm{l}$ ozone at bench scale). Also, they concluded that when cationic polymer is used as a coagulant, preozonation leads to increases removal of turbidity, TOC, and DOC. When PACl is used as a coagulant, preozonation leads either to increases or decreases in turbidity NOM removal [12].

The objectives of this research work are intended to: (1) prechlorination effect on TOC removal, (2) preozonation effect on TOC removal. (3) Comparing between prechlorination and preozonation effect on TOC removal. (4) Varying contact time effect of preozonation and prechlorination effect on TOC removal.

\section{Materials and methods}

\subsection{Waters samples and materials}

Clay, kaolin, humic acid in powder form used for simulation of raw water with desired turbidity and TOC. Commercial $60 \%$ chlorine used for prechlorination, which is used in the Tehranpars Water Treatment Plants. The humic acid was purchased in powder form of U. S. Acros Company. The ozonator model COG of Arda Company used for preozonation.

\subsection{Analysis methods}

Experiments were carried out at room temperature in a batch mode. Bench scale preozonation and prechlorination was performed. First, the raw water with turbidity of 20 NTU simulated with clay and kaolin. Then, desired TOC concentration $(4,8$, and $12 \mathrm{mg} / \mathrm{l})$ simulated with adding of humic acid in powder form. Commercial $40 \%$ ferric Chloride (that is used in the Tehranpars Water Treatment Plants) used as a coagulant. Standard jar test procedures used to evaluate ferric Chloride requirements and the primary water quality parameters.

The model water rapidly mixed for $2 \mathrm{~min}$. During this period, the $\mathrm{pH}$ of the water adjusted to the desired range by addition of $0.02 \mathrm{~N}$ sulphuric acid or $0.1 \mathrm{~N}$ sodium hydroxide. The beakers transferred to a six-place jar-test apparatus, and the water mixed at $35 \mathrm{rpm}$ for $30 \mathrm{~min}$. The beakers removed from the jar-test apparatus, and contents allowed settling quiescently for $30 \mathrm{~min}$. The $500-\mathrm{ml}$ aliquots treated with different coagulant dosage at the same $\mathrm{pH}$.

According to Primary Drinking water Standards of USEPA (1997), Turbidity must be less than $0.5 \mathrm{NTU}$ in $95 \%$ of samples per month. Thus, the ferric chloride optimum dosage for removal of turbidity in compliance with standard obtained for TOC of $4 \mathrm{mg} / \mathrm{l}$. According to Primary Secondary Water Standards of USEPA (1997), TOC of filtered water should be less than $2 \mathrm{mg} / \mathrm{l}$ (or less than 2.0 SUVA) [9]. 


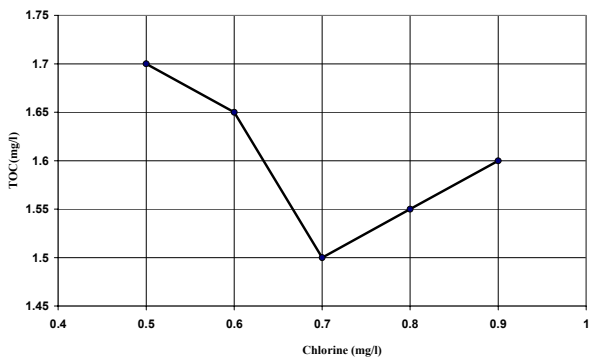

Figure 4: Chlorine effect on TOC removal.

Thus, the ferric chloride optimum dosage for removal of TOC in compliance with standard obtained for TOC of $4 \mathrm{mg} / \mathrm{l}$. Then optimum $\mathrm{pH}$ identified. In alternative 1 the optimum coagulant dosage and optimum $\mathrm{pH}$ determined $9 \mathrm{mg} / \mathrm{l}$ and 6.0, respectively. In alternative 2, TOC removal investigated with prechlorination. Thus, the chlorine optimum dosage for maximum removal of TOC determined. In alternative 3, TOC removal investigated with preozonation and ozone optimum dosage for maximum removal of TOC determined.

Finally, 3 alternatives compared with another. TOC analyzed using a TOC analyzer according to standard method [2].

\section{Results and discussion}

\subsection{Results}

\subsubsection{No preoxidation, prechlorinatiom and preozonation effects on TOC removal of $4 \mathrm{mg} / \mathrm{l}$}

Results of ferric chloride jar-test experiments for turbidity removal are shown in figure 1. As illustrated in figure 1, the optimum dosage for turbidity removal is $6 \mathrm{mg} / \mathrm{l}$. Figure 2 demonstrates the optimum dosage for TOC removal. In general, removal of both turbidity and TOC in the Jar test results was good. The optimum dosage for turbidity removal is $9 \mathrm{mg} / \mathrm{l}$.

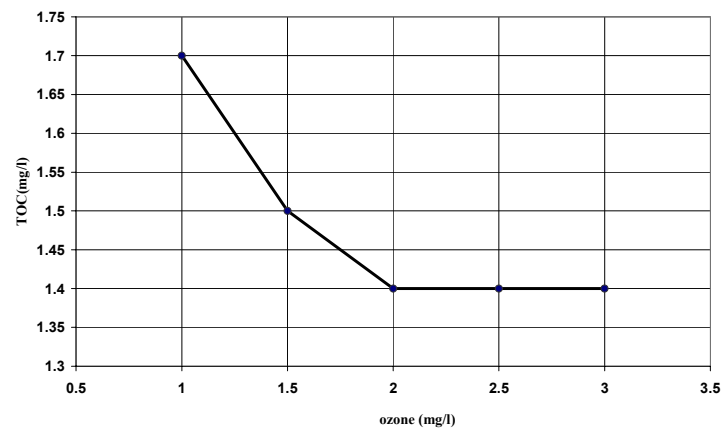

Figure 5: Ozone effect on TOC removal. 
Figure 3 demonstrates that the optimum range of $\mathrm{pH}$ for TOC removal is 66.5. The addition of chlorine before coagulation with ferric chloride increased removal of organic matter. Figure 4 shows results for Jar test experiments conducted at $\mathrm{pH}$ 6. Finally, the addition of ozone before coagulation with ferric chloride increased TOC removal. Figure 5 shows results for Jar test results.

As illustrated in figures 4 and 5, the optimum dosage of Prechlorinatiom and Preozonation are 0.6 and $2 \mathrm{mg} / \mathrm{l}$, respectively.

\subsubsection{No preoxidation, prechlorinatiom and preozonation effects on TOC removal of 8 and $12 \mathrm{mg} / \mathrm{l}$}

The results are as same as 3.1.1. Thus, the results listed at tables 1 and 2. Also, figure 7 illustrated the results.

\subsection{Discussion}

\subsubsection{No preoxidation}

Data taken from the entire jar test results in which ferric chloride used as a coagulant that is shown that required coagulant dosage for TOC removal increases with TOC increment. Figure 8 demonstrates relation between required optimum dosage of ferric Chloride and TOC removal.

Lowering $\mathrm{pH}$ to range of 6-6.5 causes to increase removal efficiency of TOC.

\subsubsection{Prechlorination, coagulation}

In general, when chlorine added to humic acid synthetic waters at $\mathrm{pH} 6.5$, removal of turbidity and organic matter slightly increased. The results of analysed data are presented in figure 4.

Lowering $\mathrm{pH}$ during enhanced coagulation increases the disinfection efficiency of chlorine. The US Environmental Protection Agency (USEPA) contact timetables for chlorine reflect this change in disinfection efficiency relate to $\mathrm{pH}$.

\subsubsection{Preozonation, coagulation}

The addition of ozone before coagulation with ferric chloride increased removal of turbidity and organic matter. These effects appeared after only 5 min of ozone contact time before coagulation addition. No definitive trend was observed with ozone contact time.

A comparison of ozonation and no ozonation shows that the addition of ozone had a beneficial effect on TOC removal.

A comparison of no ozone and applied ozone dosage of $2 \mathrm{mg} / 1$ dosage shows that the $2 \mathrm{mg} / \mathrm{l}$ dosage had a beneficial effect on turbidity removal and TOC removal. TOC removal was the reduction in negative surface charge following ozonation. The charge-neutralizing effect of preozonation may act in concert with the cationic polymer to decrease the ferric chloride to turbidity removal, thus providing "excess" ferric chloride to aid in the removal of TOC that would normally not be removed. The removal of the low-molecular-weight hydrophilic organic species is likely attributed to increased specific interactions between the organic materials and ferric chloride, followed by hydrophobic expulsion of 
NOM-ferric chloride. The fact that the change in EPM seemed to occur on approximately the same time scale as the changes observed in the coagulation experiments supports this argument.

As illustrated in table 2, specific ozone dosage of $0.5 \mathrm{mg}$ per $\mathrm{mg}$ TOC applied in the removal of TOC.

The reduction of TOC will decrease the demand and decay rate use result of the decrease in reactive material. Both of these reductions result in a lower ozone dosage required to achieve equivalent disinfection efficiency. Ozonation, when applied before enhanced coagulation, can sufficiently change the remove low molecular weight, non humic fraction.

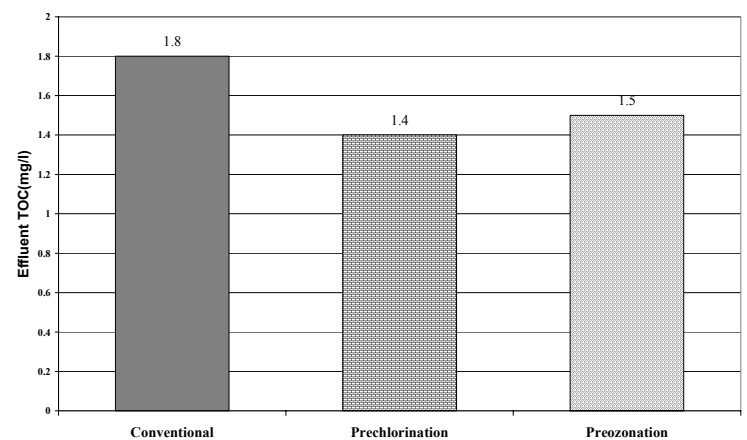

Figure 6: A comparison of conventional (no preoxidation), preozonation and prechlorination.

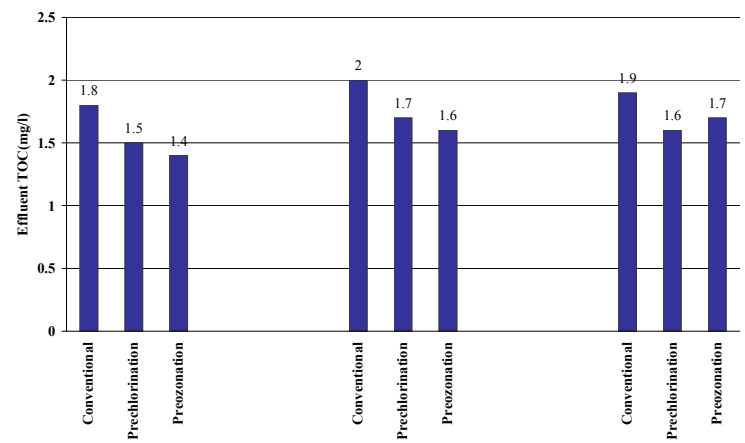

Figure 7: A comparison of conventional (No Preoxidation), Preozonation and Prechlorination at TOC of 4, 8, and $12 \mathrm{mg} / \mathrm{l}$ (left to right).

\subsubsection{Comparison of settled water TOC at no preoxidation, prechlorination and preozonation}

The authors observed detrimental effects of non oxidation, prechlorination, and preozonation on TOC removal when ferric chloride used as a coagulant. 
As illustrated in figure 6, a comparison of settled water TOC at no preoxidation, prechlorination, and preozonation shows that addition of ozone had a beneficial effect on both turbidity and TOC removal. A comparison of ozone and chlorine shows that ozone had a beneficial effect on both turbidity and TOC removal in low TOC concentration of influent water. Adversely, in high TOC concentration, chlorine had a beneficial effect on both turbidity and TOC removal. But, the effect of prechlorination and preozonation on coagulantparticle-NOM interactions are subtle and complex. Thus, use of prechlorination and preozonation as a coagulant aid will not likely be its primary application.

Table 1: Jar test results for various TOC concentrations.

\begin{tabular}{|l|c|c|c|}
\hline Optimum Dosage for turbidity removal & 6 & 30 & 60 \\
\hline Optimum Dosage for TOC removal & 9 & 40 & 70 \\
\hline Optimum pH & 6.5 & 6.5 & 6.5 \\
\hline
\end{tabular}

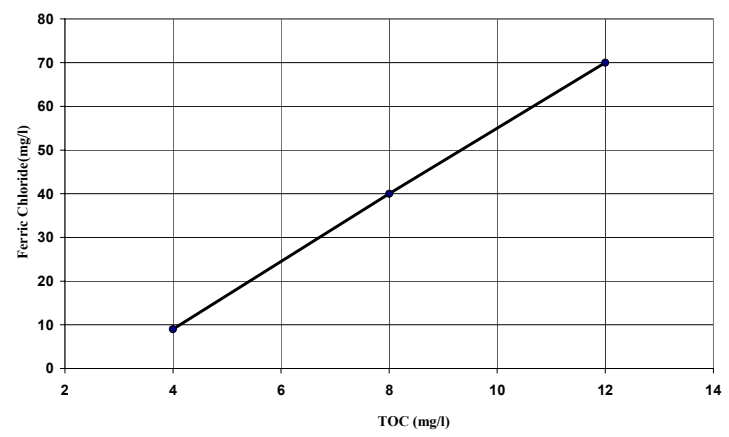

Figure 8: Required optimum ferric Chloride dose for TOC removal.

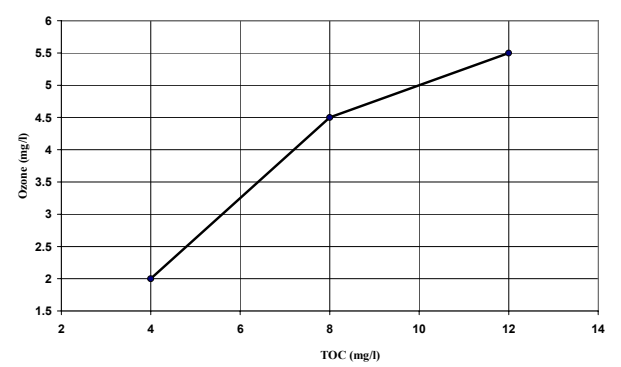

Figure 9: Required optimum ozone dose for TOC removal. 
Table 2: Maximum TOC removal with No Preoxidation, Prechlorination, and Preozonation.

\begin{tabular}{|l|c|c|c|}
\hline Alternative & TOC of $4 \mathrm{mg} / 1$ & TOC of $8 \mathrm{mg} / 1$ & TOC of $12 \mathrm{mg} / 1$ \\
\hline No Preoxidation & 1.8 & 2 & 1.9 \\
\hline Prechlorination & 1.4 & 1.6 & 1.7 \\
\hline Preozonation & 1.5 & 1.7 & 1.6 \\
\hline
\end{tabular}

\section{Conclusions}

Based on the results of the described experiments and condition; the authors drew the following conclusions.

- When ferric chloride used as a coagulant, prechlorination and preozonation lead to decrease in settled water turbidity and TOC at the conditions tested.

- When ferric chloride used as a coagulant, required dosage increased with influent TOC increment.

- When ferric chloride used as a coagulant, preozonation leads to increase removal of turbidity and TOC. These increases are apparent after only a few minutes of contact time.

- Specific ozone dosage of about $0.5 \mathrm{mg}$ per mg TOC (applied ozone dosage of approximately 2, 4.5, and $5.5 \mathrm{mg} / \mathrm{l}$ ) aids in the removal of TOC.

- $\quad$ Ozone had a beneficial effect on both turbidity and TOC removal in low TOC concentration of influent water. But, in high TOC concentration, chlorine had a beneficial effect.

- Varying the preozone contact time from 5 to $30 \mathrm{~min}$ has little effect on settled water turbidity and TOC for the conditions tested.

The effect of prechlorination and preozonation on coagulant-particle-NOM interactions are subtle and complex. Thus, use of prechlorination and preozonation as a coagulant aid will not likely be its primary application.

\section{Acknowledgements}

The authors thank the research deputy of University of Tehran which supported this study financially.

\section{References}

[1] Amy, G.L., Sierka, R.A., Bedessem, J., Price, D., Tan, L., 1992. Molecular size distributions of dissolved organic matter. J. Am. Water Work Assoc. 84 (6), 67-75.

[2] APHA. Standard Methods for the Examination of Water and Wastewater. 1995. AWWA, WEF. 
[3] Becker, W.C. Impact of Ozonation on coagulation: Model and Natural water Studies. Doctoral dissertation, The John Hopkins University, Baltimore (1995).

[4] Chiang P.C., E.E. Chang, C.H. Liang. 2002. NOM characteristics and treatabilities of ozonation processes. Chemosphere 46 (2002) 929-936. www.elsevier.com/locate/chemosphere.

[5] Crozes, G., White, P., Marshall, M., 1995. Enhanced coagulation: its effect on Nom Removal and chemical costs. J. Am. Water Work Assoc. 87 (1), 78-89.

[6] Edwards, M., Benjamin, M.M. 2002. Effect of Preozonation on Coagulant-NOM-Interactions. Jour. AWWA, 84:63.

[7] Jacangelo, J.G., N.L., Reagua, K.M. Aieta, E.M. Kranser S.W., McGuire, M.J., 1989. Ozonation assessing its role in the formation and control of disinfection by-products. J. Am. Water Work Assoc. 81 (8), 74-84.

[8] Hoehn H., Co-Chair Andrea Dietrich, Co-Chair and Daniel Gallagher. July 27, 2001. July 27, 2001. The effect of predisinfection with chlorine dioxide on the formation of haloacetic acids and trihalomethanes in a drinking water supply. Master of Science in Environmental Engineering. The Virginia Polytechnic Institute and State University.

[9] Kawamura s., 2000. Integrated Design and Operation on Water treatment Facilities. John Wiley and Sons Press. CA.

[10] Ken C., Steve V., Bill B., and Mark C. 2000.secendory effects of enhanced coagulation and softening. Jour. AWWA. Vol. 92. No. 6. pp. 63-75.

[11] Letterman, Raymond, ed. 1999. Water Quality and treatment: A Handbook of Community Water Supplies. New York, NY: McGraw-Hill.

[12] Orren D. Schneider and John E. Tobiason. 2000. Preozonation effects on coagulation. JOURNAL AWWA .Vol. 92, No. 10 pp. 74-87.

[13] Owen, D.M., Amy, G.L., Chowdhury, Z.K., Paode, R., Mccoy, G., Viscosil, K., 1995. NOM characterization and treatability. J. Am. Water Work Assoc. 87 (1), 46-63.

[14] Tae-Wook Ha, Kwang-Ho Choo, and Sang-June Choi. Effect of chlorine on adsorption/ultrafiltration treatment for removing natural organic matter in drinking water. 2004. Journal of Colloid and Interface Science 274 (2004) 587-593 www.elsevier.com/locate/jcis.

[15] W. Liua, H. Wua, Z. Wang, S.L. Ong, J.Y. Hu, W.J. Ng. Investigation of assimilable organic carbon (AOC) and bacterial regrowth in drinking water distribution system. 2001. Water Research 36 (2002) 891-898. 